\title{
Tráfico de drogas e encarceramento feminino: intersecções de gênero e
}

\author{
Liciane Barbosa de Mello \\ Osmar Belusso² \\ Recebido em março de 2020 \\ Aceito em junho de 2020
}

\section{RESUMO}

O presente artigo busca fazer uma reflexão acerca dos processos de criminalização dos conflitos de gênero relacionados a sistema de justiça e prisões. Inicialmente, expomos os números acerca do sistema prisional feminino presentes no relatório do Departamento Nacional de Informações Penitenciárias (Depen), chamando atenção para o crescimento exponencial de mulheres presas, especialmente por crimes relacionados à Lei de Drogas nos últimos anos. A partir disso, realizamos uma breve discussão acerca da legislação penal sobre drogas no Brasil e então buscamos traçar um diálogo entre o trabalho de Angela Davis sobre a obsolescência das prisões e de Dina Alves a respeito da interseccionalidade de gênero, raça e classe na produção da punição. Por fim, propomos algumas questões que poderão servir como auxílio de futuras análises e construção de instrumentos de enfrentamento do fenômeno do encarceramento feminino.

Palavras-chave: Encarceramento feminino; Seletividade Penal; Tráfico de drogas.

\section{Drug trafficking and women's incarceration: intersections of gender and race}

\begin{abstract}
The present article aims to make a reflection upon the criminalization process of the gender conflicts related to the justice system and prisons. Initially, we show the numbers of the feminine prison system present in the National Department of Penitentiary Information (Depen) report, calling attention for the exponential growth of women imprisoned, especially for crimes related to the Drug Law over the last few years. Based on that, we carry out a brief discussion about the penal legislation on drugs in Brazil and then seek for tracing a dialogue between Angela Davis work about the obsolescence of prisons and Dina Alves work about the intersectionality of gender, race and social class in the production of punishment. At last, we bring forward some questions that can assist future analyses and the construction of instruments to face the feminine incarceration phenomenon.
\end{abstract}

Keywords: Women's incarceration; Criminal selectivity; Drug traffic.

A partir da década de 1990, há uma importante intensificação no fenômeno do aprisionamento em todo o território nacional. Esse momento histórico é marcado por

\footnotetext{
${ }^{1}$ Doutoranda no Programa de Pós-Graduação em Ciência Política na Universidade Federal do Rio Grande do Sul (UFRGS). Bolsista CAPES. bm.liciane@gmail.com.

${ }^{2}$ Mestrando no Programa de Pós-Graduação em Sociologia da Universidade Federal do Rio Grande do Sul (UFRGS). Porto Alegre, Brasil. osmarbelusso@gmail.com.
} 
diversos processos em curso, como o agravamento gradativo da violência urbana, aqui representado principalmente através do crescimento significativo nas taxas de homicídios e no encarceramento nos grandes e médios centros urbanos da América do Sul (AZEVEDO; CIFALI, 2015, p. 105). Não por acaso, a tendência das reformas legislativas brasileiras nas últimas duas décadas foi no sentido de expansão das normas penais voltadas à regulamentação e sanção de segmentos da vida social que anteriormente não eram criminalizadas. Assim, por meio da criminalização de novas condutas, do endurecimento de penas e da redução de garantias processuais até então consolidadas no ordenamento jurídico brasileiro, o direito penal passa a ser o recurso por excelência acionado para solucionar todos os tipos de conflitos e problemas sociais (AZEVEDO, 2004).

Por consequência, as pretensões de remodelação do sistema de justiça e a expectativa de avanço nos processos de democratização do Estado e da sociedade, especialmente frente à promulgação da Constituição Federal de 1988, acabaram dando lugar a agendas políticas cujas pautas reforçaram práticas já bastante estabelecidas: “mais polícia, mais prisão, mais pena, mais armamento" (LIMA; SINHORETTO, 2011, p. 134). A não efetivação de direitos básicos no país revela-se como um grave problema social, na mesma medida em que o desenvolvimento de uma sociedade justa e igualitária vira um grande desafio. A falta de uma transição democrática efetiva expõe uma lacuna considerável no campo da segurança pública. Amplia-se, enquanto isso, o slogan de "direitos humanos para humanos direitos" e consolida-se a modalidade de subcidadania - onde o acesso aos serviços públicos básicos ou é inexiste ou é precário. É nesse cenário que o encarceramento em massa se insere, alcançando uma importância inafastável tanto do debate político-militante quanto acadêmico.

Muito embora o encarceramento em massa no Brasil seja um fenômeno social multifacetado e multicausal, o advento da Lei no 11.343/o6, popularmente conhecida por Lei de Drogas, representa um elemento essencial na progressão do número de pessoas presas. Com dispositivos ainda mais severos, a nova Lei de Drogas confere ao crime de tráfico de drogas ilícitas (art. 33 da referida Lei) um grande número de condutas passíveis de incriminação (dezoito ações diferentes), uma amplitude punitiva 
maior (de 5 a 15 anos de reclusão) e novas possibilidades de procedimentos para apuração.

Nesse cenário, o delito de tráfico de drogas alcança altos índices de aprisionamento. Em que pese as prisões decorrentes desta infração penal incidam de forma acentuada na população carcerária masculina, como fica claro pela relação de números absolutos, a análise proporcional da população feminina indica que esse grupo é atingido de modo muito particular. É nesse debate que o presente artigo busca se inserir. Através de um levantamento de dados estatísticos e da bibliografia especializada no tema, busca-se propor uma reflexão que relacione o crime de tráfico de drogas com o encarceramento de mulheres, sob uma análise centrada em teorias que discutam a obsolência punitiva e a interseccionalidade de gênero, raça e classe.

\section{Uma primeira contextualização: o encarceramento em números}

Em busca de uma contextualização primeira do fenômeno do encarceramento em massa, recorrentemente faz-se uso de uma série de levantamentos já amplamente disseminados no campo da segurança pública. Entre tais documentos, o Levantamento Nacional de Informações Penitenciárias, com dados oriundos do INFOPEN (SANTOS, 2017), é um importante recurso na exposição do panorama prisional no país. Os dados sistematizados pelo levantamento apontam a existência de cerca de 726.354 pessoas presas no Brasil. No entanto, a capacidade de atendimento do sistema penitenciário nacional corresponde, em tese, ao número de 423.242, revelando um expressivo déficit carcerário de 303.112 vagas. A taxa de prisão no Brasil por 100 mil habitantes é de 349,78. Muito embora os estados possuam realidades bastante heterogêneas quando comparados entre si, ao considerar que em todos eles o número de vagas prisionais foi excedido, é possível concluir que o fenômeno da superpopulação carcerária seja um problema de amplitude nacional.

Entre os tipos penais com maior incidência nas motivações das prisões, o delito de roubo figura entre a maior causa de prisão (31,88\%), seguido de crimes 
relacionados ao tráfico de drogas $3(29,26 \%)$ e furto $(14,15 \%)$. Além da criminalização ostensiva dos delitos de natureza patrimonial e envolvendo substâncias entorpecentes, o uso irrestrito da prisão provisória para réus aguardando julgamento também pode ser compreendido como um importante fator que contribui para as altas taxas de aprisionamento, especialmente em virtude da maleabilidade da sua fundamentação “pelo risco à ordem pública” (ANDRADE, 2012, p. 301).

Segundo o relatório INFOPEN Mulheres (SILVA, 2019), voltado exclusivamente à exposição dos dados acerca da população prisional feminina, do total de pessoas privadas de liberdade apresentado anteriormente, aproximadamente 37.828 são mulheres. O documento aponta para o mesmo problema de déficit de vagas da população carcerária geral, considerando que existem 31.837 vagas no sistema prisional feminino, o que resulta em um déficit de 5.991 vagas. É possível, no entanto, que o número real de mulheres em privação de liberdade seja ainda maior, tendo em vista que os últimos números divulgados pelo governo federal, através do relatório mencionado, são de dezembro de 2016 e nem todos os estados haviam repassados os respectivos dados ao Departamento Penitenciário Nacional (DEPEN). No que diz respeito à taxa de aprisionamento feminino do Brasil, houve um aumento exponencial de $455 \%$ entre os anos de 2000 e 2016 . No início deste período, a taxa de mulheres privadas de liberdade era de 6,5 para um grupo de 100 mil habitantes, sendo que atualmente essa taxa chega a 35,52 por 100 mil mulheres (SILVA, 2019).

O maior número de mulheres privadas de liberdade no país encontra-se no estado de São Paulo, com 12.520 presas, representando sozinho 31,6\% do total da população prisional feminina nacional. Em seguida estão os estados de Minas Gerais, com 3.365 presas, e Paraná, com 2.758 presas. No outro extremo encontra-se o estado do Amapá, com o menor índice de encarceramento feminino, com 108 mulheres em situação de prisão. Em que pese o contingente prisional mais expressivo, em números absolutos, esteja no estado de São Paulo, em termos da maior taxa de aprisionamento

\footnotetext{
3 Optamos por manter a terminologia "crime relacionado ao tráfico de drogas" em detrimento de somente "crime de tráfico de drogas" ou assemelhados, como forma de atentar para as diversas condutas criminalizadas na Lei no 11.363/o6, como a associação para o tráfico de drogas e o tráfico internacional de drogas.
} 
por grupo de 100 mil mulheres no país, encontram-se os estados do Acre (96,8 por 100 mil), seguido de Rondônia (93,4 por 100 mil) e Mato Grosso do Sul (92,2 por 100 mil).

Ainda de acordo com o relatório temático INFOPEN Mulheres (SILVA, 2019), o perfil majoritário encontrado na população prisional feminina, a começar pelo recorte etário, é composto por jovens de 18 a 29 anos, (47,33\%). Além disso, os dados apontam que aproximadamente $44,42 \%$ das mulheres presas não concluíram o ensino fundamental e $63,55 \%$ são negras. No que tange ao tipo penal que motivou a prisão dessas mulheres, a maioria foi sentenciada ou aguarda julgamento em razão de algum crime relacionado ao tráfico de drogas ilícitas (cerca de 59,9\%). As demais tipificações possuem, comparativamente, pouca expressão, sendo elas, respectivamente, referentes ao roubo $(12,90 \%)$, furto $(7,8 \%)$ e homicídio $(6,96 \%)$. Nesse quesito, o estado do Rio de Janeiro chama a atenção em razão da sua taxa acentuada, onde cerca de $82,4 \%$ da população carcerária feminina é composta por mulheres presas por crimes relacionados ao tráfico de entorpecentes.

As conclusões que se pode chegar, através desse breve levantamento quantitativo acerca do cenário populacional prisional brasileiro, é que (i) o crescimento da população carcerária é uma tendência que atravessa as última décadas; (ii) embora o número absoluto de mulheres presas seja menor comparado com o número de homens presos, a taxa de crescimento indica uma curva de progressão mais acentuada que no caso da população masculina; (iii) há uma importante relação entre os crimes relacionados ao tráfico de drogas e o fenômeno do encarceramento em massa.

Considerando a proporção atingida pelos crimes relacionados ao tráfico de drogas no sistema carcerário nacional, cabe aqui uma breve discussão bibliográfica do contexto em que se insere a legislação penal sobre drogas no Brasil, em especial a atual Lei de Drogas (Lei no 11.343/o6), bem como os seus efeitos no fenômeno do encarceramento em massa.

\section{Contextualização da legislação de drogas no Brasil}


Muito embora o tratamento legal destinado ao tema envolvendo entorpecentes no mundo não tenha se desenvolvido de forma homogênea, é possível identificar no século XX um importante marco histórico para o fortalecimento de posturas proibicionistas: a "Guerra às Drogas". O regime empregado pelos EUA no final da década de 196o fundamentou-se na forte repressão ao uso e à comercialização de substâncias psicoativas. Essa postura rapidamente obteve amplo apoio no circuito político internacional, incentivando reformas legislativas em diversos Estados, como o Brasil. Desse modo, as últimas décadas estruturaram o novo foco da segurança pública no país com a regulamentação da matéria atinente às drogas ilícitas por meio da legislação penal, ou seja, através da criminalização de condutas, o endurecimento de penas e o recrudescimento de garantias processuais para as pessoas acusadas de crimes relacionados ao tráfico de drogas.

Diversos acordos internacionais reafirmaram o compromisso mundial de proibição às drogas no século XX, ainda que inicialmente se tenha adotado justificativas mais amenas, com a mobilização de uma gramática da regulação. Contudo, após a pactuação de três tratados internacionais, os países signatários enfim consolidaram a repressão como o principal recurso de "combate às drogas', estabelecendo categorias criminais capazes de abarcar desde a sua produção, sua comercialização e mesmo o seu uso, inspirados pelo que se pode denominar por "utopia proibicionista" (RODRIGUES, 2010, p. 8).

No caso do Brasil, o modelo de gestão repressiva da droga é consolidado a partir da década de 1960, quando o país ingressa de forma definitiva no cenário internacional de controle de drogas, configurando uma ideologia de diferenciação social, cujo pressuposto é distinguir as representações do consumidor e do traficante, do doente e do delinquente (TORCATO, 2016). O mercado ilegal do tráfico de drogas se propagou no país no fim da década de 70 e, desde então, pode ser considerado um novo poder que vem modificando cada vez mais o panorama da segurança pública (ZALUAR, 2004). A promulgação da Lei no 11.343/o6 teve uma importante contribuição nesse novo panorama, uma vez que os tipos penais envolvendo o tráfico de drogas e seus correlatos compõem uma das principais causas para o aprisionamento das pessoas, sobretudo mulheres. 
A forma como o Estado encara essa questão não obtém êxito na diminuição desse comércio específico, na maioria das vezes controlado por pessoas com grande influência política e social, como grandes fazendeiros, empresários, negociantes e banqueiros que possuem vínculos transnacionais que operam como facilitadores para a produção, comercialização e também lavagem de dinheiro (ZALUAR, 2004).

A atual legislação penal sobre drogas vigente no Brasil é responsável pela maior parte do encarceramento de mulheres. Os presídios em sua maioria são locais que remetem aos primórdios do objetivo de sua criação: um grande depósito de pessoas. As prisões foram originalmente destinadas ao confinamento de mendigos, pobres, vadios e pequenos criminosos (aqueles que a sociedade não desejava ver ou conviver), onde realizavam atividades laborais e recebiam correção moral (SALLA; LOURENÇO, 2014). Os crimes utilizados para motivar a grande parcela de prisões no Brasil não são considerados crimes violentos (tráfico e furto), no entanto, o país produz 175 mortes violentas intencionais por dia em um único ano (LIMA et al, 2018). Isso nos leva a problematizar a questão do sistema penal ter como objetivo diminuir a violência através do aprisionamento, uma vez que taxa de mortes violentas atualmente no Brasil é 30,8 por 100 mil habitantes (LIMA et al, 2018).

A Lei no 11.343/o6 foi criada, como proposta legislativa da CPI do Narcotráfico, com o propósito de modificar aquela em vigor há 30 anos, a Lei no 6368/76, também conhecida como a lei de tóxicos. O ponto alto da nova legislação era a diferenciação no tratamento de usuário e traficante, no qual o primeiro seria vinculado ao sistema de Saúde, e o segundo seguiria sendo processado junto ao sistema de justiça criminal, mas com uma considerável elevação na pena estabelecida pela lei de 1976. Campos (2015), denomina essa mudança como o "dispositivo médico-criminal de drogas”, referindo-se ao dispositivo adotado como uma nova maneira de administração estatal da droga. De um lado, o objetivo era endurecer a pena para a figura do traficante, e de outro, deixar de prender aquele identificado como usuário.

No Brasil, mesmo quando uma política estatal na área de segurança pública e justiça criminal sofre alguma alteração e deslocamento em direção ao aumento dos direitos e garantias fundamentais (fim de pena de prisão ao usuário), privilegia-se dentro do sistema de justiça criminal a pena de prisão como resposta estatal (CAMPOS, 2015, p. 17). 
Os dispositivos do ordenamento jurídico brasileiro que tratam da matéria não diminuíram o número de pessoas encarceradas. Pelo contrário, como já demonstrado, houve o aumento do número de mulheres encarceradas, ante a criação de um sistema normativo, subjetivo, que não diferencia quantidades de drogas e pune de forma discricionária, seletiva e desproporcional. Punir com mais severidade o traficante atende a um anseio popular por mais punição, como instrumento de intimidação do Estado ao indivíduo que comete um crime, pois assim poderia desencorajar o cometimento de novos delitos. No entanto, o aumento exponencial dos índices de aprisionamento sugerem que sequer esse objetivo foi alcançado pela lei penal.

O crime do tráfico de drogas está tipificado no artigo 33 da Lei no 11.343/o6, enquanto o uso de drogas ilícitos se encontra no tipo penal do artigo 28 da mesma Lei. Tal diferenciação, entretanto, sofre com a ausência de precisão legislativa, uma vez que não define com clareza e objetividade os critérios a serem utilizados na acusação desses crimes, considerando que embora o usuário não seja punido com prisão, permanece como uma conduta criminalizada.

Nesse sentido, a primeira ação classificatória dependerá do policial que fizer a abordagem e a apreensão. O policial opera, desse modo, como a ponta do sistema penal (BARBOSA, 2017). O exercício da sua função implicará em tomar decisões rápidas que terão consequências para terceiros. Assim como o Poder Judiciário e o Ministério Público, também terá poder discricionário, mas sem o mesmo aparato e preparo dos atores jurídicos. Inclusive, o agente policial aparece majoritariamente como testemunha nos casos de tráfico de drogas, muitas vezes como a única. Assim, "é esse agente que vai narrar os fatos como crime e oferecer à justiça criminal os 'indícios' de 'materialidade' e 'autoria', elementos fundamentais para o início de uma ação penal” (JESUS, 2016, p. 20).

A Lei no 13.840/19, que no momento aguarda ser sancionada pelo Presidente da República não deve representar uma solução suficiente para a questão da subjetividade da aplicação legal e do encarceramento massivo, uma vez que aumenta a pena mínima de prisão para o traficante de cinco para oito anos e estabelece a possibilidade de uma pena menor a depender da quantidade e do tipo de droga apreendida, ficando a cargo 
do juiz avaliar cada caso ${ }^{4}$. O novo texto também prevê mais punição ao usuário, dispondo de dois tipos de internação: voluntária e involuntária (prazo máximo de noventa dias) e fortalece o papel das comunidades terapêuticas, ignorando a função dos Centros de Atendimento Psicossocial (CAPS), além de enfraquecer as pautas antimanicomiais.

O ordenamento jurídico brasileiro é marcado historicamente por um viés patrimonialista que persiste até os dias de hoje (ODON, 2013). Isso é reforçado pelos dados apresentados acerca do sistema penitenciário nacional, onde os crimes contra o patrimônio figuram como o tipo penal com maior incidência nas prisões. A interpretação histórico-social indica que a ordem no Brasil foi construída através de um sistema jurídico que elegia um inimigo da ordem pública. Segundo Odon, "na ordem instituída, o ator violento é sempre aquele 'estranho' que não foi corretamente normalizado/socializado, ou que talvez nem tenha salvação, e o direito penal brasileiro se acostumou a tratá-lo como inimigo" (ODON, 2013, p. 390). Para o autor, o direito penal serviu como "lei geral do Império" para mediar conflitos, conduzir a mão-deobra escrava e condicionar o pobre livre ao trabalho. Da mesma forma, a classe dominante, tomada por medo de uma guerra civil, criou um "aparato burocrático racional-legal" que via na repressão e punição a única forma de diálogo entre sociedade e Estado.

\section{O encarceramento em questão}

Como efetivamente compreender um fenômeno complexo como o encarceramento em massa, desenhado aqui através de levantamentos estatísticos que apresentam uma curva crescente bastante expressiva? Como se apreende com profundidade as razões que transformam a mulher negra no alvo preferencial do sistema de justiça criminal?

Dina Alves (2017) nos oferece uma pista muito interessante ao trabalhar com o conceito de feminização da pobreza e da punição, que concebe que tanto o processo de

\footnotetext{
${ }^{4}$ BRASIL, 2019. "Senado aprova projeto que altera política nacional sobre drogas". Disponível em: $<$ https:/www12.senado.leg.br/noticias/materias/2019/05/15/senado-aprova-projeto-que-alterapolitica-nacional-sobre-drogas $>$.
} 
marginalização da mulher negra ao acesso às esferas de produção, consumo e cidadania quanto a sua participação na economia ilegal, em especial o tráfico de drogas ilícitas, principalmente na condição de "coadjuvante", fazem parte do mesmo fenômeno. Isto é, a feminização da pobreza e da punição diz respeito à dominação da mulher negra através da precarização ou extinção de direitos e garantias sociais e consequente vulnerabilidade social, bem como o movimento de sua criminalização e seu aprisionamento. São dois lados do mesmo processo.

Tal perspectiva se vincula com leituras históricas sobre o encarceramento em massa nos Estados Unidos, a partir do desmantelamento do que se entendia por Estado Social (que em alguma medida, ainda que deficitário, conseguia suprir algumas demandas da população mais vulnerável) e o fortalecimento de um Estado (cada vez mais) Penal, no qual os serviços de assistência social existentes são bastante precarizados, senão descontinuados, passando a operar mecanismos de vigilância, controle e estocagem de pessoas excedentes do mercado de trabalho (WACQUANT, 2007).

Nesse contexto se insere a filósofa estadunidense Angela Davis, argumentando pela existência de um continuum penal entre o período escravagista e a democracia contemporânea, não sendo possível afirmar que houve, de fato, uma transição na pósabolição que extinguisse as práticas, pensamentos e estruturas que mantinham e reproduziam a sujeição, subordinação e desumanização de mulheres negras. Assim, as raízes históricas oriundas do período escravagista determinam, ainda hoje, o "lugar" e o "não-lugar" da mulher negra. De escravas domésticas para empregadas domésticas, do Brasil colonial para o Brasil democrático e contemporâneo, a cozinha e a prisão ocuparam e ainda ocupam historicamente os "lugares" das representações do corpo negro, em especial o da mulher negra. Ser mulher, negra e pobre no Brasil determina uma posição de extrema vulnerabilidade social (ALVES, 2017).

Para Angela Davis (2019) a prisão está introjetada de tal maneira na sociedade como algo tão natural que se torna muito difícil, ou talvez impossível, imaginar um mundo sem a sua existência. Ou mesmo o fato de imaginar crime separado de castigo, nos levando a crer que a prisão é algo incontestável e estabelecido como única forma de lidar com as situações e com as pessoas que cometem condutas consideradas 
criminosas. Isso quer dizer que, mesmo considerando a sua consolidação social, não há uma dimensão ontológica no aprisionamento. A pena de prisão alcança o status de recurso por excelência para a resolução de conflitos no ocidente, principalmente a partir da segunda metade do século XVIII, consolidando o que Pires $(2004 ; 2017)$ denomina como a teoria da racionalidade penal moderna, que diz respeito à estrutura de pensamento que obstaculiza a formulação do direito criminal e intensifica os processos que levam ao encarceramento em massa.

De acordo com Angela Davis (2019), um sistema de encarceramento em grande escala foi promovido e alimentado pelo que denomina como complexo industrialprisional, que se desenvolveu a partir da década de 1980, na chamada Era Reagan. O complexo industrial-prisional se tornou uma importante fonte de lucro para muitos empresários, pois foi criado para substituir o complexo industrial-militar no período após o fim da Segunda Guerra Mundial. Com isso, uma economia da punição passou a operar nos Estados Unidos: as cidades que experimentavam graves crises financeiras passaram a sediar casas prisionais. Ao contrário do que o senso comum pode indicar, a partir da perspectiva da especulação imobiliária, a construção de presídios pode representar um fator positivo para o aquecimento da economia, uma vez que esses lugares são mantidos através de uma vasta gama de serviços como construção, transporte, alimentação, recursos humanos, itens de higiene, etc. Embora a privatização da gestão de presídios componha um exemplo nítido e direto desse fenômeno, não é a única forma com que penitenciárias podem movimentar a economia e, inclusive, operar em uma lógica de lucro.

Angela Davis (2019) argumenta que o presídio, por mais contraintuitivo que possa parecer, foi criado como forma de se destinar aos transgressores da lei um tratamento "mais humanizado", uma vez que substituiria os castigos físicos e sobretudo a pena capital, "oportunizando", em tese, a reflexão sobre o crime cometido. Além disso, a punição não deixava de apresentar fortes dimensões de gênero, pois as mulheres não eram consideradas sujeitos detentores de direitos e, sem possuírem direitos, os mesmos não poderiam ser restringidos através da pena privativa de liberdade. Nesse caso, no entanto, o castigo seria administrado de maneira informal, especialmente por intermédio das relações conjugais. As mulheres que infringissem as 
normas poderiam ser submetidas a punições estabelecidas pelos maridos. Segundo Davis, "a persistência da violência doméstica é uma evidência dolorosa desses modos históricos de punição por gênero" (DAVIS, 2019, p. 49).

O debate público sobre a expansão do sistema prisional dos Estados Unidos deixou as mulheres de fora, colocando-as em ambientes completamente hostis e masculinizados, em geral marcados por tratamentos violentos e com forte presença de agressões sexuais (como, por exemplo, através das revistas íntimas). Ainda, a filósofa chama atenção para a centralidade do gênero na compreensão do sistema de punição estatal:

\footnotetext{
Embora os homens constituam a ampla maioria dos prisioneiros no mundo, aspectos importantes da operação da punição estatal são ignorados quando se presume que as mulheres são marginais e, portanto, não merecem atenção. A justificativa mais frequente para a falta de atenção dada às prisioneiras e às questões específicas em torno do encarceramento feminino é a proporção relativamente pequena de mulheres entre as populações carcerárias ao redor do mundo. $\mathrm{Na}$ maioria dos países, a porcentagem de mulheres entre as populações carcerárias gira em torno de 5\% (DAVIS, 2019, p. 70).
}

Diante disso, mostra-se necessário a inclusão de mulheres nas discussões sobre reforma no sistema prisional, tendo em vista o crescente índice de aprisionamento feminino, como apresentado anteriormente. Além disso, existem particularidades que o sistema carcerário precisa levar em consideração, como a recorrente situação de abandono da mulher presa por parte da família ou amigos. Ao contrário do que acontece com a maioria dos homens encarcerados, grande parcela das mulheres ainda precisam enfrentar o período de aprisionamento sem receber visitas da sua rede de apoio. Outra questão importante diz respeito às condições estruturais dos presídios. Considerando que originalmente foram construídos enquanto uma instituição exclusivamente masculina, muitos estabelecimentos não permitem o exercício adequado do direito de reprodução, gestação e maternidade da mulher presa. Nesse sentido, não há a previsão suficiente de celas adaptadas para gestantes, berçários, creches e centros de referência materno infantil. Os dados do relatório INFOPEN Mulheres apontam que apenas $16 \%$ das penitenciárias no território nacional possuem celas ou dormitórios adequados para gestantes. 
As dimensões de raça e classe perpassam as relações de gênero, uma vez que mulheres negras compõem o maior número do sistema prisional feminino, seguindo os mesmos marcadores sociais da população carcerária masculina. Nesse sentido:

\footnotetext{
Deve-se levar em conta os trâmites dos processos judiciais que frequentemente operam para a reprodução da injustiça social, com base no entrelaçamento da discriminação de gênero, raça-etnia e classe, desde a abordagem policial até o sentenciamento e a reclusão de mulheres (GERMANO, MONTEIRO, LIBERATO, 2018, p. 29).
}

Angela Davis (2019) aponta que os estabelecimentos prisionais para mulheres supostamente seriam espaços para instigar a domesticidade feminina, para que essas, quando estivessem em liberdade novamente, fossem aptas a desempenhar o papel de boas esposas e boas donas de casa. Contudo, argumenta a autora, essa "nova vida" era reservada principalmente a mulheres brancas, já que as mulheres negras acabavam indo para o serviço doméstico nas casas de famílias brancas. Além disso, mulheres negras e nativas americanas muitas vezes eram separadas das mulheres brancas e condenadas a cumprir penas em prisões masculinas (DAVIS, 2019).

\section{Considerações finais}

A seletividade da aplicação da Lei no 11.343/o6, desde os profissionais da linha de frente até os diversos atores jurídicos participantes do sistema de justiça criminal, contribuem para o fenômeno do encarceramento em massa no Brasil, sobretudo de negros, tanto homens quanto mulheres, ambos detentores dos marcadores sociais selecionados pelo poder punitivo que opera na sociedade. Em virtude disso, o olhar a este fenômeno deve ser direcionado com bastante atenção, pois a adoção de posturas centradas na punição como forma de resolução de problemas sociais, pode produzir ainda mais violências, conforme aponta a tendência dos dados expostos sobre prisão e criminalidade. $\mathrm{O}$ encarceramento não produziu efeitos concretos contra as violências presentes nas grandes cidades, tampouco foi capaz de torná-las ambientes mais seguros e livres de crimes violentos. 
O Brasil teve em vigor durante as últimas décadas do século XX uma legislação oriunda do período da ditadura militar, a qual previa, por exemplo, que o usuário de drogas poderia ser detido por até dois anos. A atualização legislativa proposta pelo advento da Lei nº 11.3.43/o6 buscava a modernização do tratamento jurídico conferido ao uso e ao comércio de drogas ilícitas, de modo a diferenciar tais situações e manter a prisão enquanto punição apenas para a figura do traficante. No entanto, o tráfico de drogas tornou-se o foco nas agendas políticas de controle e repressão. Assim, o que originalmente pretendia reduzir o número de prisões e restringir o poder punitivo estatal, acabou por alavancar o crescimento das taxas de encarceramento, não obtendo êxito em estabelecer critérios objetivos para a sua aplicação.

O crescimento exponencial do aprisionamento de mulheres é um cenário relativamente recente no Brasil e segue a tendência da criminalização seletiva operada em função da Lei de Drogas. Nesse sentido, chama atenção o número de mulheres negras presas por questões relacionadas a tráfico de entorpecentes, indicando que, assim como acontece com o homem negro no aprisionamento masculino, a mulher negra é o alvo preferencial da política repressiva. Tal seletividade reforça a existência de estruturas e agências operando através de critérios raciais, isto é, atuando e potencializa os processos de racialização dos corpos de mulheres.

\section{Referências}

ALVES, Dina. Rés negras, juízes brancos: uma análise da interseccionalidade de gênero, raça e classe na produção da punição em uma prisão paulistana. Revista CS. Cali: Facultad de Derecho y Ciencias Sociales, 2017. n. 21. p. 97-120.

ANDRADE, Vera Regina Pereira de. Pelas mãos da criminologia: o controle penal para além da (des)ilusão. Rio de Janeiro: Revan, 2012.

AZEVEDO, Rodrigo Ghiringhelli de. Tendências do controle penal na época contemporânea: reformas penais no Brasil e na Argentina. São Paulo em Perspectiva. vol. 18. n. 1. São Paulo, 2004. p. 39-48.

; CIFALI, Ana Cláudia. Política criminal e encarceramento no Brasil nos governos Lula e Dilma: Elementos para um balanço de uma experiência de governo pós-neoliberal. Civitas - Revista de Ciências Sociais, v. 15, n. 1, abr. 2015. p. 105-127. 
BARBOSA, Liciane. "Assalariados”: A narrativa jurídica punitivista sobre o tráfico de drogas. 2017. Dissertação (Mestrado em Sociologia) - Instituto de Filosofia e Ciências Humanas, Universidade Federal do Rio Grande do Sul, Porto Alegre, 2017.

CAMPOS, Marcelo da Silveira. Pela metade: as principais implicações da nova lei de drogas no sistema de justiça criminal em São Paulo. 2015. Tese (Doutorado em Sociologia) - Faculdade de Filosofia, Letras e Ciências Humanas, Universidade de São Paulo, São Paulo, 2015.

DAVIS, Angela. Estarão as prisões obsoletas? 3. ed. Rio de Janeiro: Difel, 2019.

GERMANO, Idilva Maria Pires; MONTEIRO, Rebeca Áurea Ferreira Gomes; LIBERATO, Mariana Tavares Cavalcanti. Criminologia Crítica, Feminismo e Interseccionalidade na Abordagem do Aumento do Encarceramento Feminino. Psicologia: Ciência e Profissão, Brasília, v. 38, n. 2, p. 27-43, 2018.

GISI, B.; TONCHE, J.; ALVAREZ, M.; OLIVEIRA, T. A teoria da "Racionalidade Penal Moderna” e os desafios da justiça juvenil. Plural, v. 24, n. 1, p. 124-16o, 30 ago. 2017.

IBGE. Censo Demográfico 2010: Características gerais da população, religião e pessoas com deficiência. Rio de Janeiro: IBGE, 2010. Disponível em: <https://biblioteca.ibge.gov.br/visualizacao/periodicos/94/cd_2010_religiao_deficienci a.pdf $>$ Acesso em 29 ago. 2019.

JESUS, Maria Gorete Marques de. "O que está no mundo não está nos autos": a construção da verdade jurídica nos processos criminais de tráfico de drogas. Tese (doutorado) - Faculdade de Filosofia, Letras e Ciências Humanas, Universidade de São Paulo, 2016.

LIMA, et al. Anuário Brasileiro de Segurança Pública 2018. São Paulo: Fórum Brasileiro de Segurança Pública, 2019. Disponível em: <http://www.forumseguranca.org.br/wp-content/uploads/2019/o3/Anuario-Brasileirode-Seguran\%C3\%A7a-P\%C3\%BAblica-2018.pdf>. Acesso em o7 ago. 2019.

LIMA, R. S. de; SINHORETTO, J. Qualidade da democracia e polícias no Brasil. In: LIMA, R. S. de. Entre palavras e números: violência, democracia e segurança pública no Brasil. São Paulo: Alameda, 2011. p. 129-152.

ODON, Tiago Ivo. A linguagem penal do contrato social brasileiro: o inimigo, a guerra e a construção da ordem contra a sociedade no Brasil (1822-1890). 2013. Tese (Doutorado em Sociologia) - Universidade de Brasília, DF, 2013.

PIRES, Álvaro. A racionalidade penal moderna, o público e os direitos humanos".In Novos Estudos CEBRAP, n 68, março de 2004, p. 39-6o. 
RODRIGUES, Thiago. Apresentação. In: LABROUSSE, Alain. Geopolítica das drogas. São Paulo: Desatino, 2010.

SALLA, Fernando. LOURENÇO, Luiz Claudio. Aprisionamento e Prisões. In: LIMA, R. S.; RATTON, J. L.; AZEVEDO, R. G. (Orgs.). Crime, Polícia e Justiça no Brasil. São Paulo: Editora Contexto, 2014. p. 376-381.

SANTOS, Thandara. Levantamento Nacional de Informações Penitenciárias INFOPEN Mulheres. 2. ed. Brasília: Ministério da Justiça e Segurança Pública, Departamento Penitenciário Nacional, 2017. Disponível em: $<$ http://depen.gov.br/DEPEN/depen/sisdepen/infopen-

mulheres/infopenmulheres_arte_07-03-18.pdf> Acesso em 13 ago. 2019.

SILVA, Marcos Vinícius Moura. Relatório Temático Sobre as Mulheres Privadas de Liberdade - Junho de 2017. Brasília: Ministério da Justiça e Segurança Pública, Departamento Penitenciário Nacional, 2019. Disponível em: $<$ http://depen.gov.br/DEPEN/depen/sisdepen/infopenmulheres/copy_of_Infopenmulheresjunho2017.pdf> Acesso em 10 fev. 2020.

TORCATO, Carlos Eduardo Martins. “A história das drogas e sua proibição no Brasil": da Colônia à República. Tese (doutorado) - Faculdade de Filosofia, Letras e Ciências Humanas, Universidade de São Paulo, 2016.

WACQUANT, Loic. Punir os pobres: a nova gestão da miséria nos Estados Unidos. 3. ed. Rio de Janeiro: Revan, 2007.

ZALUAR, Alba. Integração Perversa: Pobreza e Tráfico de Drogas. São Paulo: FGV, 2004 . 